\title{
Nutritional status of the children in areas affected by 2005 earthquake in northern Pakistan
}

\author{
Nausheen Hamid, Dee Bhakta and Bob Gilchrist \\ London Metropolitan University, London, UK
}

There is evidence to suggest that there has been increased prevalence of child malnutrition in disaster-struck communities ${ }^{(1-4)}$. The main aims of the present paper were to assess the nutritional status of the children aged 12-59 months in the earthquake-affected areas of Pakistan and to explore the effect of various explanatory variables on the nutritional status of these children.

The present study was a cross-sectional descriptive survey. Children aged 12-59 months were randomly selected from three areas badly affected by the 2005 earthquake in Mansehra District of northern Pakistan. Data were collected in August 2006. Anthropometric data consisted of weights and heights of children in order to determine the prevalence of malnutrition for three nutritional status indicators in children, i.e. wasting, stunting and underweight. To determine these levels individual weights and heights were compared manually with the reference population for which purpose recent WHO growth standards ${ }^{(5)}$ were used. The $95 \%$ CI for the levels of malnutrition are also reported. To explore the affects of explanatory variables socio-demographic information, information on infant feeding practices in the region and current health problems of children were collected using a structured validated questionnaire. The analysis of variables that potentially might relate to malnutrition was based on logistic models analysing regressions for binary dependent variables of three malnutrition indicators ('wasting', 'stunting' and 'underweight') $v$. various explanatory variables. The level of significance was set as $P<0.05$.

The total number of participants was 102 from eighty households. The findings showed increased prevalence of both acute and chronic child malnutrition in the affected areas of Pakistan as compared with levels reported by previous surveys in those areas ${ }^{(6-8)}$. Of the children 17.6 (95\% CI 10.1, 25.1) \% were found to be wasted, 47.1 (95\% CI 37.2, 57.0) \% were stunted and 39.2 (95\% CI $29.5,48.8) \%$ were underweight. Among children who were severely malnourished (i.e.<3sD) 4.9 (95\% CI 0.6, 9.2) were wasted, 26.5 (95\% CI 17.8 , $35.2) \%$ were stunted and 15.7 (95\% CI 17.8, 35.2) \% were underweight. Several explanatory variables were found to be important predictors of malnutrition in the region. There were increased odds of wasting in children in age-groups $\leq 35$ months as compared with children in the older age-groups. Similarly, there were sixfold increased odds for stunting in children $\leq 23$ months compared with the agegroup 48-59 months. In terms of breast-feeding and infant-weaning practices, the odds of children being wasted increased by 1.12 $(P=0.04)$ for every month if they continued to be breast-fed after 12 months of age. Similarly, the odds of children being wasted (OR 4.13; $P=0.03)$ and stunted (OR 1.79; $P=0.05)$ increased with increasing delay in weaning. Children living in smaller households had decreased odds of being stunted (OR $0.78 ; P=0.00)$ and underweight (OR 0.86; $P=0.02)$ than those living in larger households. Children who were suffering from infectious diseases had more than twice the odds of being underweight than those not suffering these infections (OR 2.55; $P=0.05$ ).

Comparison with earlier data indicates significantly increased levels of child malnutrition in areas affected by the 2005 earthquake in Northern Pakistan. However, a smaller sample size of the current study and different growth standards used to determine the levels of malnutrition should be considered when comparing with previous data. The demographic information revealed by the present study matched the demographic information reported by the National Nutrition Survey of Pakistan $(2001-2)^{(6)}$ and the UN Study conducted in the earthquake-affected region 2 months after the earthquake ${ }^{(8)}$; therefore, the sample of the present study can be said to be fairly representative of the population under study.

1. Food and Agriculture Organization (2005) Protecting and promoting good nutrition in crisis and recovery. Resource guide. ftp://ftp.fao.org/docrep/fao/ 008/y5815e/y5815e00.pdf

2. Food and Agriculture Organization (2006) The double burden of malnutrition; case studies from six developing countries. FAO Food and Nutrition Paper no. 84. ftp://ftp.fao.org/docrep/fao/009/a0442e/a0442e00.pdf

3. de Onis M, Monteiro C, Akré J \& Clugston G (1992) The Worldwide Magnitude of Protein-energy Malnutrition: An Overview from WHO Global Database on Child Growth. Geneva: WHO.

4. Connolly MA, Gayer M, Ryan MJ, Spiegel P, Salama P \& Heymann DL (2004) Lancet 364, 1974-1983.

5. Garza C \& de Onis M (2007) J Nutr 137, 142-143.

6. Pakistan Institute of Development Economics (2002) National Nutrition Survey 2001-02. Islamabad, Pakistan: UNICEF/Planning Commission of Government of Pakistan.

7. Pakistan Institute of Development Economics (2001) Nutritional Status in Pakistan: Pakistan Socio-economic Survey 1998-99. MIMAP Technical Paper Series no. 8. Islamabad, Pakistan: PIDE.

8. United Nations (2006) Health and Nutrition Survey in Earthquake Affected Areas, Pakistan. UNICEF/WFP/WHO Joint Survey in Collaboration with Ministry of Health. New York: UN. 